\title{
On the Legal Categorisation of New Plant Breeding Technologies: Insights from Communication Science and Ways Forward
}

\author{
P. Marijn POORTVLIET*, Kai P. PURNHAGEN, Reginald BOERSMA and \\ Bart GREMMEN
}

In July 2018 the Court of Justice of the European Union (CJEU) ruled that organisms obtained from most New Plant Breeding Technologies (NPBT) fulfil the requirements of the GMO definition of Directive 2001/18. Practically, organisms created with NPBT have since been legally treated as GMOs. While we do not seek to contest the judgment in itself, in the present contribution we draw attention to the effects of such a categorisation from the perspective of communication science. Extrapolating from communication research conducted in adjacent technology domains, we will argue that by putting organisms obtained from NPBT semantically in the same basket as GMOs may carry a serious risk - transferring analogous communication problems that GMOs encountered in the past, to organisms obtained from NPBT, while they may not address similar risks. Possible consequences such as these can hardly be considered at the stage of legal interpretation (such as with the CJEU). Rather, as discussion now unfolds whether and how to change the legal definition, insights from communication science and risk perception research on the effect of such a definition should be taken into account.

\section{CurRent legal Standings (AND POSSible Developments IN THE NEAR FutURE)}

New Plant Breeding Technologies (NPBTs) are ways to increase and accelerate the development of new traits in plant breeding. In its 2011 review of the state-of-the-art of these technologies, the Institute for Prospective Technological Studies (IPTS) of the Joint Research Centre (JRC) of the European Commission in cooperation with the JRC's Institute for Health and Consumer Protection (IHCP) included cisgenesis, intragenesis (technologies using transformation with genetic material restricted to the species' own gene-pool), emerging techniques to induce controlled mutagenesis or insertion (ODM, Zinc Finger Nuclease technologies 1-3) and other applications such as grafting on GM rootstocks or reverse breeding. ${ }^{1}$ The regulation and legal categorisation of NPBTs has long been subject to debate in EU law. At the policy level academic discussions across

\footnotetext{
* Email: marijn.poortvliet@wur.nl.

1 JRC/IPTS/IHCS, New Plant Breeding Techniques. State-of-the-art and Prospects for Commercial Development (Luxembourg: Publications office of the European Union 2011).
} 
disciplines have evolved around the question whether products from NPBTs are or should be subject to special regulation. ${ }^{2}$ According to some, as most NPBTs could not be separated from conventional breeding techniques, they should not be subject to special regulation. ${ }^{3}$ Others, highlighting the requirements of the precautionary principle, call for regulation following the regulations for GMOs. ${ }^{4}$ The CJEU judgment ${ }^{5}$ on the mutagenesis exemption in Directive 2001/18/EC ${ }^{6}$ (hereafter the Directive) has clarified that most NPBTs are subject to regular GM regulation in the EU. ${ }^{7}$ This interpretation of the applicable EU GM law has created a regulatory system for NPBTs which is unique in the world. ${ }^{8}$ Among the many features surrounding this CJEU decision, the most interesting one in terms of thisarticle revolves around the question whether NPBTs can be legally included in the definition of a GMO. ${ }^{9}$ The definition of a GMO is set out in Article 2(2) of the Directive: "'genetically modified organism' (GMO) means an organism, with the exception of human beings, in which the genetic material has been altered in a way that does not occur naturally by mating and/or natural recombination". Although techniques using mutagenesis are not explicitly included in the definition (see Article 2(a), (b) Directive), they are according to Article 3 lit. 1 excluded from the application of the Directive. It has hence been a question in the literature and of other stakeholders whether organisms obtained with NPBTs, of which most apply mutagenesis techniques, fall within the definition of a GMO. Opinions were divided over this question. ${ }^{10}$ Some argued that organisms obtained with mutagenesis techniques are excluded from the Directive. However, as organisms created by most mutagenesis techniques would involve modifying the genetic make-up, they would nonetheless be within the regulatory scope of the Directive. ${ }^{11}$ In particular, lawyers have pointed out the fact that the Directive differentiates between the legal requirements of its scope and its exemption. $^{12}$ Taking this further, a thorough look into the respective articles of the

2 T Sprink et al, "Regulatory hurdles for genome editing: process- vs. product-based approaches in different regulatory contexts" (2016) 35(7) Plant Cell Reports 1493.

3 New Techniques Working Group, "Final Report" (2008), available at <www.seemneliit.ee/wp-content/uploads/ 2011/11/esa_12.0029.pdf > accessed 14 February 2019.

4 Eg C Then and A Bauer-Panskus, Playing Russian Roulette with Biodiversity (Munich: Testbiotech 2017).

5 Case C-528/16, Confédération paysanne et al v Premier ministre Ministre de l'agriculture, de l'agroalimentaire et de la forêt [2018] ECLI:EU:C:2018:583.

6 Directive 2001/18/EC of the European Parliament and of the Council of 12 March 2001 on the deliberate release into the environment of genetically modified organisms and repealing Council Directive 90/220/EEC - Commission Declaration, OJ L 106, 17.4.2001, 1-39.

7 KP Purnhagen et al, "EU court casts new plant breeding techniques into regulatory limbo" (2018) 36 Nature Biotechnology 799 .

8 D Eriksson et al, "A comparison of the EU regulatory approach to directed mutagenesis with that of other jurisdictions, consequences for international trade and potential steps forward" (2018) New Phytologist, 13 December $<$ doi: $10.1111 /$ nph.15627 >

9 For a summary of the pre-judgment discussion see GF Albújar and B van der Meulen, "The EU's GMO Concept: Analysis of the GMO Definition in EU Law in the Light of New Breeding Techniques (NBTs)" (2018) 13 European Food and Feed Law Review 14.

10 Sprink et al, supra, note 2.

11 F Hartung and J Schiemann, "Precise plant breeding using new genome editing techniques: opportunities, safety and regulation in the EU" (2014) 78 The Plant Journal 742.

12 TM Spranger, "Legal analysis of the applicability of Directive 2001/18/EC on genome editing technologies" (2015), available at < bfn.de/fileadmin/BfN/agrogentechnik/Dokumente/Legal_analysis_of_genome_editing_technologies.pdf >, accessed 14 February 2019. 
Directive reveals that the mutagenesis exemption does not refer to the definition, but rather to the overall Directive. Hence, one could meaningfully argue that the mutagenesis exemption does not include a normative statement on what - or what not - to include in the definition, but rather delineates the application for the whole Directive. This reasoning was followed by neither the Advocate General nor by the Grand Chamber of the Court. Rather, the AG in his Opinion adopted the view that organisms derived from mutagenesis are in principle covered by the definition of a GMO. ${ }^{13}$ Otherwise, one would not need to exempt mutagenesis from the definition. ${ }^{14}$ This reasoning and result was taken over by the Grand Chamber of the Court, ${ }^{15}$ but not the conclusion of the AG to also exempt NPBTs based on mutagenesis from the definition. Henceforth, organisms derived from mutagenesis - including NPBTs - are legally defined as GMOs. In the present contribution, we draw the attention to the effects of such a categorisation from the perspective of communication science. ${ }^{16}$ In the next section, by extrapolating from communication research conducted in adjacent technology domains, we will argue that putting organisms obtained from NPBT semantically in the same basket as GMOs may carry a serious risk - transferring analogous communication problems that GMOs encountered in the past, to organisms obtained from NPBT, while they may not address similar risks.

\section{Categorisation Processes in DeAling With nOVel technologies}

While the legal classification of NPBT involving mutagenesis as GMOs has thus been established, so far there has been no investigation into what effects such a classification might have on the societal debate. In order to shed light on the matter, this section will first review research from communication science and risk perception research, before we present some possible scenarios in section III.

As a starting point we note that with the development of novel technologies, the general public cannot be expected to have (and typically does not have) much in-depth knowledge about the vast and variegated body of available technologies. ${ }^{17}$ Given this lack of expertise, the question arises how people go about forming evaluations of technologies ${ }^{18}$ - including NPBTs. Several alternativeshave been described. ${ }^{19}$ They can: (1) apply general scientific knowledge $;^{20}(2)$ use risk perceptions relating to other technologies as a

\footnotetext{
13 Opinion of AG Bobek delivered on 18 January 2018(1), Case C-528/16, Confédération paysanne et al v. Premier ministre Ministre de l'agriculture, de l'agroalimentaire et de la forêt, ECLI:EU:C:2018:20, para 60.

14 ibid, para 62.

15 Case C-528/16, supra, note 5, paras 27-38.

16 See, on the importance of smart communication about NPBT, L Pei and M Schmidt, "Novel biotechnological approaches to produce biological compounds: challenges and opportunities for science communication" (2019) 56 Current Opinion in Biotechnology 43.

17 R Boersma and B Gremmen, "Genomics? That is probably GM! The impact a name can have on the interpretation of a technology" (2018) 14(1) Life Sciences, Society and Policy 8.

18 M Bucchi, "Of deficits, deviations and dialogues: theories of public communication of science" in M Bucchi and B Trench (eds), Handbook of Public Communication of Science and Technology (New York: Routledge 2008) 57-76.

19 R Boersma et al, "The elephant in the room: how a technology's name affects its interpretation" (2019) 28 Public Understanding of Science 218.
} 
starting point; ${ }^{21}$ or (3) adapt existing attitudes. ${ }^{22}$ In the present contribution we are interested in how people evaluate NPBTs, that is, how they form attitudes and perceptions about these relatively unfamiliar techniques. Stemming from a generally low level of biotechnology knowledge among members of the public, ${ }^{23}$ a person's reaction is likely to be guided by informational cues and heuristics (decision rules) that aid in the interpretation of a technology. ${ }^{24}$ These cognitive processes - in combination with people's established more general technology-related opinions, openness to innovations and other individual characteristics like one's need for cognition, political values and worldviews, trust in relevant stakeholders, and personal norms and belief system, and level of information elaboration ${ }^{25}$ - will drive a person's evaluation.

An important feature of a technology is how it is labelled, which includes its name and also the name of the category the technology is associated with. As a cognitive shortcut, people can respond to novel technologies by referring to its overarching category in order to deduct an evaluation. ${ }^{26}$ To elaborate on one of those shortcuts, we will introduce the key psychological mechanism of categorisation. According to categorisation theory, people are motivated to give meaning to concepts by ordering them in logical ways. As a result, a person's knowledge is organised in categories of similar concepts. ${ }^{27} \mathrm{New}$ concepts that people are unfamiliar with can be interpreted by placing them in a category of familiar concepts that appear to be similar in some way to the unfamiliar concept ${ }^{28}-\mathrm{a}$ process called categorisation. For obvious reasons, by offering category information alongside information about a specific technology this process is importantly facilitated - especially when people have already formed attitudes about the higher-order technology category. As such, they will extend this pre-existing attitude to the target technology. ${ }^{29}$ When attitude extension occurs, attitudes about the known concept are transferred to the new concept, whereby the attitudes towards the familiar concept can be

20 DA Scheufele and BV Lewenstein, "The public and nanotechnology: How citizens make sense of emerging technologies" (2005) 7(6) Journal of Nanoparticle Research 659.

21 L Bredahl et al, "Consumer attitudes and decision-making with regard to genetically engineered food products: a review of the literature and a presentation of models for future research" (1998) 21(3) Journal of Consumer Policy 251.

22 KG Grunert et al, "Four questions on European consumers' attitudes toward the use of genetic modification in food production" (2003) 4(4) Innovative Food Science \& Emerging Technologies 435.

23 A Bostrom, and RE Löfstedt, "Nanotechnology risk communication past and prologue" (2010) 30 Risk Analysis 1645; Eurobarometer, Special Eurobarometer 341, Wave 73.1: Biotechnology, conducted by TNS Opinion \& Social on request of European Commission (2010).

24 Eg S Chen and S Chaiken, "The heuristic-systematic model in its broader context" (1999) 15 Dual-process theories in Social Psychology 73; RE Petty and JT Cacioppo, "The elaboration likelihood model of persuasion" in Communication and Persuasion (New York: Springer 1986) 1.

25 AA Anderson et al, "The 'nasty effect': online incivility and risk perceptions of emerging technologies" (2014) 19 Journal of Computer-Mediated Communication 373; SS Ho et al, "Factors influencing public risk - benefit considerations of nanotechnology: assessing the effects of mass media, interpersonal communication, and elaborative processing" (2013) 22 Public Understanding of Science 606; DM Kahan et al, "Biased assimilation, polarization, and cultural credibility: an experimental study of nanotechnology risk perceptions" (2008) The Cultural Cognition Project at Yale Law School; BC Mulder et al, "Explaining end-users' intentions to use innovative medical and food biotechnology products" (2014) 9 Biotechnology Journal 997.

26 Scheufele and Lewenstein, supra, note 20.

27 E Rosch, "Principles of categorization" in E Rosch and BB Loyd (eds), Cognition and Categorization (Hillsdale, NJ: Lawrence Erlbaum 1978) 27.

28 B Loken et al, "Categorization theory and research in consumer psychology: category representation and categorybased inference" in CP Haugtvedt et al (eds), Handbook of Consumer Psychology (New York: Lawrence Erlbaum Associates 2008) 133. 
used to make decisions about the unfamiliar concept. So, their established evaluation of the technology category can serve as a relatively efficient cognitive frame of interpretation.

Recent perception research on genomics provides important insights into how people evaluate novel and unfamiliar technologies. Genomics aided plant breeding is a technique that does not employ artificial recombination of genes. First, it tests whether certain genes are present in the parental plants. Then it uses traditional breeding techniques, followed by testing whether certain genes are present in the offspring (instead of observing whether specific traits are expressed, which is much less efficient). As such, technically it does not fall into the category of genetic modification. However, and perhaps not surprisingly given the semantic resemblance shared by the terms genomics and GM, it has been reported that people tend to believe that genomics equals genetic modification. As a result a person can make an unfavourable evaluation of genomics because of the controversies associated with GM. ${ }^{30}$ This very much resonates with the notion of a stigma described by Löfstedt. ${ }^{31}$ Given a pre-existing negativity associated with a certain category, it will be almost impossible to realise a more favourable evaluation later on.

It has been noted that the transfer of controversies from GM to genomics is particularly ironic, since plant scientists consider genomics often as an uncontroversial alternative to GM. ${ }^{32}$ From the perspective of reproduction and related risks, genomics is better understood when people apply their feelings and beliefs about traditional breeding rather than about GM. It is clear that, with all the controversies surrounding GM, the link between GM and genomics can potentially harm the development of genomics and the acceptance of any new genomics-assisted food products when they reach the consumer. Indeed, it has been shown that when people are confronted with the name genomics this makes them evaluate related information in a similar way to genetic modification. Importantly, when the term genomics was replaced with the term natural crossing their evaluations were more similar to those for traditional breeding (and, for that matter, more favourable). ${ }^{33}$

\section{SynthesIS}

So far, we have given overviews of the current legal situation concerning NPBTs, and we have reviewed relevant research from communication science and psychology on how categorisation processes operate in people's judgement concerning novel technologies.

29 Ie NPBTs; AV Muthukrishnan and BA Weitz, "Role of product knowledge in evaluation of brand extension" in RH Holman and MR Solomon (eds), Advances in Consumer Research (Provo, UT: Association for Consumer Research 1991) 18 407-413.

30 F Van Dam and H De Vriend, "Publieksonderzoek Genomics 2002" Den Haag, the Netherlands: Stichting Consument en Biotechnologie (2002); R Hall "CBSG2012 A public-private partnership in the plant sciences" in H Zwart (ed), CSG Researchers Days (2010), Symposium organized at the meeting of CSG Centre for Society and the Life Sciences, Berg en Dal, Netherlands.

31 RE Löfstedt, "Risk communication guidelines for Europe: a modest proposition" (2010) 13(1) Journal of Risk Research 87.

32 Boersma et al, supra, note 19; $\mathrm{M}$ Tester, and $\mathrm{P}$ Langridge $\mathrm{P}$ "Breeding technologies to increase crop production in a changing world" (2010) 327(5967) Science 818-822.

33 Boersma et al, supra, note 19. 
In this paper we put forward the argument that legal categorisations (or, for that matter, classifications) can spill over to mental categorisations.

What implications will this have for legal debates and developments in the specific case of NPBTs? By putting organisms obtained with NPBTs in the same basket as GMOs, the CJEU, wittingly or unwittingly, categorised organisms obtained with NPBTs as GMOs in the sense that psychology uses this term. It is hence likely that, simply by doing that, societal debates surrounding GMOs will also be transferred to organisms obtained with NPBTs. As a consequence, the toolbox of major technologies which plant scientists have developed during the past decades will become societally tainted. Instead of working towards an exemption for all tools separately, they were clustered under the name 'NPBTs'. Compared to the name genomics, the name NPBTs is less informative, which seems to work as an effective 'societal shield'. Because there is no semantic resemblance shared by the terms NPBTs and GM, people have almost no reason to believe that NPBT equals genetic modification. This means that the making of unfavourable evaluations of NPBT because of the controversies associated with GM is expectedly unlikely. However, the verdict of the CJEU links all future developments in plant breeding to GM since 'NPBTs' is a catch-all, generic term that refers to all ongoing developments. Thus the attempt to build an effective societal shield by renaming technologies as NPBTs not only failed but could also backfire on future plant breeding technologies.

This would not be a problem in principle if both also featured comparable properties in terms of associated hazards. Debates on GM revolve around many aspects, including consumer choice, acceptability, ethics, and safety issues in terms of individual health and environmental protection. To establish whether GMOs and organisms obtained from NPBTs share comparable properties in these respects depends on the standard against which one compares them. Regarding safety-related issues, the legal standard is stipulated by Article 2(2) of the Directive, and the Court has decided that, when applying it, it was met. However, when looking at the standard of comparability from a scientific perspective, this might not hold.

Most NPBTs could indeed be seen as being different from classical GM technologies, as the gene edit is a more precise one and mimics natural developments. Likewise, it is much clearer in most cases that risks for biodiversity are not at stake. In addition, many classical techniques used to create GMOs can be considered as increasing the odds for additional, unforeseen effects compared with more targeted and effective NPBTs. ${ }^{34}$ Conversely, the induced changes, while indeed being more targeted and specific, have often more impact than classical GM technologies. What most - but not all - NPBT have in common with classical GM techniques is the involvement of a gene editing step. ${ }^{35} \mathrm{We}$ hence do not deny that some NPBT share essential features with classical GM techniques. However, in several respects they are also different. This could have also been accounted for in the judgments, as these aspects would have been much better been dealt with in the interpretation of the exemptions of the Directive. As the debate between

\footnotetext{
34 See K Purnhagen et al, "The European Union Court's Advocate General's Opinion and new plant breeding techniques" (2018) 36 Nature Biotechnology 573.

35 Hartung and Schiemann, supra, note 11.
} 
Advocate General Bobek ${ }^{36}$ and the Grand Chamber of the Court ${ }^{37}$ figured, this is also the place for debate whether NPBT using mutagenesis are similar to conventional GM mutagenesis techniques. Because of the Directive's scope/exemption approach, however, organisms obtained from both techniques would be "tagged" as GMOs, with the potential to trigger the above-mentioned classification effect in societal debate.

\section{WAYS FORWARD AND CONCLUSION}

An interesting question would be what members of the general public would have thought without the CJEU's judgment. To answer this question would require empirical testing, but it may be argued that for most members of the general public a link between a technique like, for instance, CRISPR/Cas and GM will not easily be made. That is, we would not expect that the public would identify NPBTs as GM when no context was offered to them.

However, in cases of such uncertainty, and as we have argued in Section II, people will look for any cues or information to draw an inference. We posit that a heavily mediacovered court ruling that this technique was judged under the GM umbrella will more likely than not nudge a person to follow that logic and infer that CRISPR/Cas is a form of GM. Although this is not necessarily wrong, it might mean that "traditional" GM and CRISPR/Cas will be perceived as similar in ways they are not, which can result in making particular risk inferences. ${ }^{38}$ This, in turn, can potentially result in the rejection of a NBPT even when it does not contain the controversial aspect itself. For example, an important critique against GM is the haphazard, "random" (and "unnatural") way in which DNA is recombined. With CRISPR/CaS, DNA can be modified with rigorous precision (using a naturally occurring mechanism).

The current scope/exemption approach of the Directive has the potential to trigger a classification effect, by which societal debates around NPBTs will quasi automatically be put in the same basket as debates surrounding GMs. As a consequence, even if, as AG Bobek $^{39}$ and Dutch authorities proposed, ${ }^{40}$ future legislation will exempt NPBTs from the scope of the Directive, organisms obtained with NPBTs will still be legally classified as GMOs, triggering the classification effect in societal debates. Here we do not take sides in this. Even more, we acknowledge that the CJEU was operating within a limited remit, which finds its boundaries within the methods of legal interpretation. We rather propose to the legislator that future legislation should take this effect into account when evaluating changes of the law.

\footnotetext{
36 Opinion of AG Bobek, supra, note 13.

37 Case C-528/16, supra, note 5, paras 27-38.

38 PM Poortvliet et al, "Performativity in action: how risk communication interacts in risk regulation" (2016) 7 European Journal of Risk Regulation 213.

39 Opinion of AG Bobek, supra, note 13.

40 See < www.tweedekamer.nl/downloads/document?id=4a511f59-d46d-4d87-80d3-1bd9f0957028\&title=Proposal $\% 20$ for $\% 20$ discussion $\% 20 \mathrm{on} \% 20$ actions $\% 20$ to $\% 20$ improve $\% 20$ the $\% 20$ exemption $\% 20$ mechanism $\% 20$ for $\% 20$ gen etically\%20modified\%20plants\%20under\%20Directive\%202001\%2F18\%2FEC.pdf > accessed 14 February 2019.
} 